\title{
The Research and Implementation of Sports teaching Management System in Colleges LIRONG ZHANG ${ }^{1, a}$ \\ ${ }^{1}$ XIAMEN UNIVERSITY OF TECNOLOGY, XIAMEN CITY 361024,China \\ aLIRONGZHANG1028@yeah.net
}

\begin{abstract}
Keywords: educational management system; structural design methods; research; implementation; management system;
\end{abstract}

\begin{abstract}
This paper mainly discusses the current college educational administration management information system research background, system planning, system analysis, overall design (conceptual structure design and logical structure design) and other design (code design, input and output design, man-machine dialogue design and safety design). The system is based on B/S and $\mathrm{C} / \mathrm{S}$ combination, the use of structured development methods, making full use of the mature computer technology for digital management of the educational administration management information.
\end{abstract}

\section{Introduction}

With the rapid development of Internet technology, the digital campus construction to achieve the teaching network, become the key colleges and universities to realize the management modernization and informatization. Many domestic colleges and universities to establish the educational administration management information system, but most of them are limited to static Webpage LAN, the lack of the backstage Web database support, cannot interact information dissemination of timely information sharing, the degree is low. Therefore, the development of new educational management system based on Internet, the realization of educational administration information management digitization has practical significance. This paper introduces in detail the complex network structure based on the process, analysis and design of educational management information system by using structured development methods. The construction mode of the system there are two main structure mode: C/S (Client Server, namely the client / server) mode and the browser / server) mode.[4] The structure model by the client and server two layers, in the form of logic and transaction logic on the client, data logic and data storage in server. The client software in general have applications and related database interface, when the change of system applications and the need to change the logic of transaction processing, the application on each client also need to update, system maintenance more trouble.

\section{The development of sports management system platform in Colleges and Universities}

\section{(1)Characteristics of management system platform}

A relatively complete college sports information system including the hardware, system software, system software, application software to support the identification of several parts. Overall, they have the following characteristics: (1)Overall, the system included teaching, after-school training, mass sports, education scientific research, logistics subsystems, each subsystem can be subdivided into several function modules. Such as sports teaching management subsystem can include students PE Achievement and student training records, the system is also equipped with statistical analysis, this let the sports information management more scientific characteristics. (2) Normalized, need for data processing and data analysis are often. The medical profession is concerned; the computer can provide more comprehensive, faster and more correct sports service than artificial, save a lot of manual inspection, summary, and the print job. For 
example, the query of students sports scores, as long as the input number, name and other information, it can be shown that the student's semester grade and to print. (3) Periodic, information system of college sports has the characteristics of obvious cycle. (4) Binding, college sports information system should allow sports and computer system to really pay attention to the combination of two kinds of science and technology links, do a good job application of sports information system.(see Fig 1) [1]

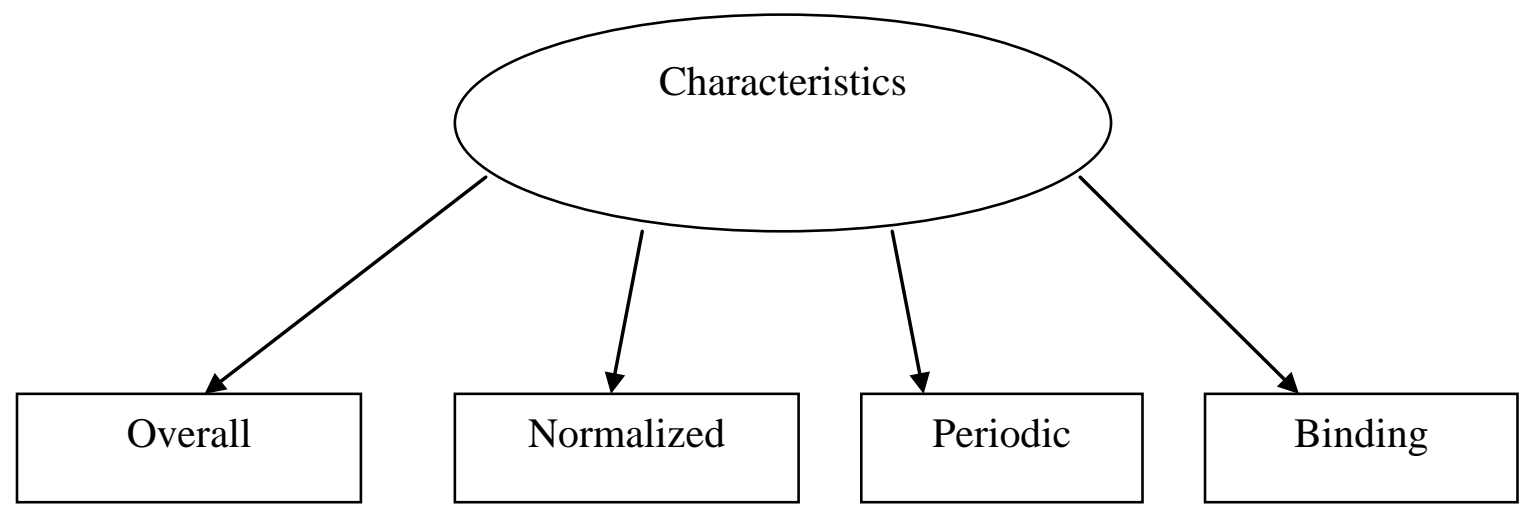

Fig 1.A good job application of sports information system

(2)The books of sports resources

Universities sports management departments are there exists a unique reference room, these data room size is differ, but the basic function of consistent. Because of computer and Internet technology has made considerable progress, the old reading methods have been gradually eliminated, virtual data network which is carrying more and more important function, a lot of department reference room and reading room of the library books are old, little person make inquires, gradually disappeared in people's field of vision. [3] So to establish the complete system of College Sports Management Department of network library appears to be imperative, but its operation is not difficult, only need to focus on several computers and LANs can be connected, then the students can easily login network library and all kinds of paper search the web, get the most cutting-edge, the most timely information.

\section{College sports management system application platform}

Our country university physical education, always adhere to the "health first, strong physique" theme, [2]recently launched a series of extracurricular sports activities, in order to reverse the physical quality of high school, college students group is generally low situation. But the enthusiasm and initiative, how to stimulate students to participate in physical exercise, called the problem faced in order to physical education workers to. Therefore, college sports system platform targeted forms of exercise testing, it is necessary to track and review, to supervise the students to complete the overall physical training, continued to test for the health of the students, and gradually establish the student quality database. This application mode is still in the blank state in many colleges and universities, the reason is the implementation of hinder greatly, the training of students enthusiasm is very low, the reason is that the study pressure and family pressure double effect, but also has some universities in the database of students' physical quality is explored applications, such as the establishment of the smart card machine than over the track, students complete after the exercise the campus IC card inserted, recorded on the day of the exercise content to backup and. 


\section{Structured development methods}

Structured development methods, mainly in accordance with the "top-down, stepwise refinement method to develop system", including system planning, system analysis, system design, system implementation and system operation and maintenance of the several stages. In the system analysis, using top-down, layer decomposition, have gradually realized the abstract to the concrete problems in the process; in the system design, first consider the optimization of the whole system, and then consider the optimization problem of local; then the system implementation, insists the bottom-up, after the first local whole, forming a complete system through standardized module links. And object oriented development method with object-oriented program design method of OOP (Object Oriented Programming) [3] developed. The basic idea is based on the problem space in nature, segmentation, identification of the objects and their mutual relationship, establishing the information model of the problem space. On the basis of system design, software module is for structural system corresponding object and relation.

In addition, although the prototype method more accord with people understanding of the general law of things, but the main function of the teaching management system in advance can clear the basic design of the system, so the choice of structured development methods. [2]The general goal of the educational administration management system mainly includes two aspects: one is system planning to activities of daily educational administration of the school to carry on the management, analysis, control to improve management efficiency and the management level; the second is foreign to be able to publish daily information timely, convenient school educational status outside understand, on campus, outside between the establishment of an efficient, fast communication channels.

\section{The relationship of teaching management and students}

Teaching management, teacher to teacher registration archives of student registration, student records, and file to change; teaching management, examination arrangements for each semester examination, after the end of registration by teacher student achievement, for statistical analysis of student achievement; , at the end of each semester, students on the basis of each department next term the courses next semester classes, teachers accept the teaching task; at the end of each semester, the school for teacher appraisal rating, at ordinary times, teachers, students, managers, leaders at all levels also ready to query all kinds of teaching information. The educational administration management system management system the top DFD Tutu 6 educational administration management system of the first layer of DFD Tutu 7 educational management system with DFD map data dictionary data flow diagram is described the system which of several parts, each part of the connection between the and so on, but no description of each component in the system of meaning. The data dictionary is mainly used to describe the data flow diagram in data flow, data storage, processing and external entities. There are six types of entries in the data dictionary: data element, data structure, data flow, data storage, and processing, external entity. [5]

\section{Conclusion}

In this paper, the development status of colleges and universities for teaching management system, has conducted the thorough research, analyzes the importance and necessity of the educational administration management in the daily teaching activities. After the system of multi range analysis, more accurate grasp of the functional requirements of system, based on the theory of the system is analyzed and designed in detail. Development of educational management system of a college is a huge project. But my ability and energy is limited, the system also has many defects, analysis and research such as the main design of the educational administration of the system of school management functions, while for the network based on the external function simply 
mentioned; in addition, the school system also has a lot of lack. In future, it will complete the implementation part of the external design of the system as a whole system, striving for perfection through continuous, making it more adapted to the need of application.

\section{Acknowledgements}

Xiamen education scientific planning project(13029).

\section{References}

[1] Han Jungian; extracurricular sports activities is an important way of college physical education teaching [J], Science Education, 2007(12), 32-36.

[2] Pei Suiting, application of happy sports thought in Physical Education in Colleges and universities,[J], consumer guide, 2008(13),12-14.

[3] Sun Wei, College PE Teaching Influences on College Students' Psychological [J], Journal of Jilin Institute of Physical Education, 2005(01), 07-11.

[4] Wen feng, college physical education and social sports practice thinking [J], Chinese, 2007(28), 22-25.

[5] Zhou Wei; Zhou Jing, humanism of PE Teaching in Colleges and universities [J], Journal of Xi'an Physical Education University; 2005 (01), 47-55. 